\title{
S-Nitrosoglutathione Attenuates Airway Hyperresponsiveness in Murine Bronchopulmonary Dysplasia
}

\author{
Thomas M. Raffay, Andrew M. Dylag, Juliann M. Di Fiore, Laura A. Smith, \\ Helly J. Einisman, Yuejin Li, Mitchell M. Lakner, Ahmad M. Khalil, Peter M. MacFarlane, \\ Richard J. Martin, and Benjamin Gaston
}

Division of Neonatology (T.M.R., A.M.D., J.M.D.F., P.M.M., R.J.M.) and Division of Pediatric Pulmonology (L.A.S., H.J.E., Y.L., B.G.), Department of Pediatrics, Rainbow Babies and Children's Hospital, and Department of Pharmacology (M.M.L.) and Department of Genetics and Genome Sciences (A.M.K.), Case Western Reserve University School of Medicine, Cleveland, Ohio Received February 27, 2016; accepted July 28, 2016

\section{ABSTRACT}

Bronchopulmonary dysplasia (BPD) is characterized by lifelong obstructive lung disease and profound, refractory bronchospasm. It is observed among survivors of premature birth who have been treated with prolonged supplemental oxygen. Therapeutic options are limited. Using a neonatal mouse model of BPD, we show that hyperoxia increases activity and expression of a mediator of endogenous bronchoconstriction, S-nitrosoglutathione (GSNO) reductase. MicroRNA-342-3p, predicted in silico and shown in this study in vitro to suppress expression of GSNO reductase, was decreased in hyperoxia-exposed pups. Both pretreatment with aerosolized GSNO and inhibition of GSNO reductase attenuated airway hyperresponsiveness in vivo among juvenile and adult mice exposed to neonatal hyperoxia. Our data suggest that neonatal hyperoxia exposure causes detrimental effects on airway hyperreactivity through microRNA-342-3p-mediated upregulation of GSNO reductase expression. Furthermore, our data demonstrate that this adverse effect can be overcome by supplementing its substrate, GSNO, or by inhibiting the enzyme itself. Rates of BPD have not improved over the past two decades; nor have new therapies been developed. GSNO-based therapies are a novel treatment of the respiratory problems that patients with BPD experience.

\section{Introduction}

Globally, more than $11 \%$ of babies are born before 37 weeks of gestation (premature), and the number of premature births is increasing worldwide (Blencowe et al., 2012). Bronchopulmonary dysplasia (BPD) is the major pulmonary morbidity of extreme prematurity, with an estimated 14,000 diagnoses made annually in the United States (Lemons et al., 2001; Van Marter, 2009) and annual healthcare expenditures in excess of $\$ 4.5$ billion (Maitre et al., 2015). After their initial care, half of

This work and T.M.R. were supported in part by a generous endowment from the Rainbow Babies and Children's Foundation career development award in pediatrics and through the National Institutes of Health National Institute of Child Health and Human Development [Grant K12HD057581-05]. T.M.R. and A.M.D. are participants in the National Institutes of Health Loan Repayment Program. B.G., Y.L., and L.A.S. were supported by the National Institutes of Health National Heart, Lung, and Blood Institute [Grant 1P01HL101871].

B.G. is a scientific consultant to Nivalis Therapeutics.

Portions of these data have been presented as abstracts at the following meetings: Raffay T, Dylag A, DiFiore J, Martin R, MacFarlane P, Gaston B (2015) S-nitrosoglutathione aerosol reverses compliance and resistance changes found in a neonatal murine model of hyperoxic airway reactivity; and American Thoracic Society meeting; 2015 May 20; Denver, CO; and Raffay T, Li Y, Martin R, Gaston B (2015) Neonatal hyperoxia increases lung S-nitrosoglutathione reductase expression and activity in a mouse model of bronchopulmonary dysplasia. Pediatric Academic Societies meeting; 2015 Apr 27; San Diego, CA. dx.doi.org/10.1124/mol.116.104125. extremely premature patients will be rehospitalized in early childhood for respiratory causes (Furman et al., 1996). Follow-up studies of children and young adults born prematurely show evidence of impaired pulmonary function, manifesting signs of bronchospastic airway hyperresponsiveness (Kim et al., 2006; Lum et al., 2011) and obstructive pulmonary disease with decreased predicted forced expiratory volume in 1 second (Vrijlandt et al., 2006; Fawke et al., 2010; Vollsæter et al., 2013), decreased predicted forced expiratory flow (Fawke et al., 2010; Vollsæter et al., 2013), and reduced exercise capacity (Vrijlandt et al., 2006). Indeed, airway hyperreactivity and asthma-like symptoms are common long-term pulmonary consequences of both premature birth and BPD (Greenough, 2006, 2013; Jaakkola et al., 2006; Baraldi et al., 2009).

S-nitrosothiols (SNOs) are molecules in which nitric oxide is bound to a cysteine thiol. They regulate the biologic activity of many target proteins (Foster et al., 2009). One such SNO is S-nitrosoglutathione (GSNO), an endogenous bronchodilator, which is 100 -fold more potent than the asthma medication theophylline (Gaston et al., 1994). GSNO is capable of relaxing smooth muscle in both a guanylate cyclase-dependent (Mayer et al., 1998) and -independent manner (Perkins et al., 1998) in part through decreasing calcium sensitivity (Pabelick et al.,

ABBREVIATIONS: BCA, bicinchoninic acid; BPD, bronchopulmonary dysplasia; BSA, bovine serum albumin; eNOS, endothelial NOS; GSNO, S-nitrosoglutathione; GSNOR, GSNO reductase; iNOS, inducible NOS; miR, micro-RNA; NOS, nitric oxide synthase; PBS, phosphate-buffered saline; qRT-PCR, quantitative reverse-transcription polymerase chain reaction; Rrs, respiratory system resistance; SNO, S-nitrosothiol; 2C/NOA, copper-cysteine reagent and nitric oxide analysis. 
2000). GSNO reductase (GSNOR; also known as alcoholdehydrogenase 5) is extensively expressed in lung tissue and regulates endogenous SNO levels through the enzymatic breakdown of GSNO to oxidized glutathione and ammonia (Liu et al., 2001). In a homeostatic manner, GSNOR catabolic activity can increase under conditions of elevated nitric oxide synthase (NOS) activity, specifically inducible NOS (iNOS) and endothelial NOS (eNOS) (Bhandari et al., 2006; Brown-Steinke et al., 2010). Airway levels of GSNO are decreased in pediatric cases of severe asthmatic respiratory failure (Gaston et al., 1998), and airway expression of GSNOR is elevated in asthma patients (Que et al., 2009; Marozkina et al., 2015). Consistent with these findings, GSNOR is a critical modulator of airway hyperreactivity in asthmatic animal models (Fang et al., 2000; Que et al., 2005; Ferrini et al., 2013; Blonder et al., 2014).

In the perinatal period, infants with evolving BPD are frequently treated for airway hyperreactivity (Mhanna et al., 2009; Slaughter et al., 2015), but first-line therapies such as $\beta 2$-adrenergic agonists lack consistent bronchodilator efficacy (Motoyama et al., 1987; Kovacs et al., 1990; Denjean et al., 1992) and have not been shown to prevent BPD nor facilitate weaning of respiratory support (Denjean et al., 1998). Of note, older children with BPD also have airway hyperreactivity that is distinct from allergic T-helper-2-high asthma (Halvorsen et al., 2005; Siltanen et al., 2011; Filippone et al., 2013) and may have minimal or even a paradoxical response to traditional asthma medications (Yuksel and Greenough, 1993; De Boeck et al., 1998; Baraldi et al., 2005). Novel treatments are needed in this high-risk patient population. We hypothesized that increased GSNOR activity could underlie the perinatal airway hyperreactivity observed in BPD and thus GSNO repletion would be therapeutic.

We tested this hypothesis in a hyperoxic murine model of BPD and airway hyperreactivity (Raffay et al., 2014). Murine lung development continues postnatally and is similar to the premature human lung (Amy et al., 1977; Berger and Bhandari, 2014). Hyperoxia exposure in neonatal mice creates a lesion very similar to human BPD (Warner et al., 1998) with characteristic long-term alveolar and parenchymal remodeling (Nold et al., 2013; O'Reilly et al., 2014), manifesting increased airway reactivity (Takeda et al., 2009; Raffay et al., 2014; Regal et al., 2014; Wang et al., 2014). We used this model to investigate the role of GSNOR in BPD airway hyperreactivity. We demonstrate that neonatal hyperoxia increases GSNOR expression and activity, in part through a microRNA (miR), and GSNO-based treatments can abolish BPD airway hyperreactivity. This novel mechanism underlying the pathophysiology of bronchospasm in murine BPD is particularly encouraging because there have been no effective new treatments for BPD in decades, and GSNO-mimetic compounds are already in clinical trials for other lung diseases.

\section{Materials and Methods}

Animal Hyperoxic Exposure. Animal protocols were approved by the Institutional Animal Care and Use Committee at Case Western Reserve University (Cleveland, OH). Timed pregnant C57BL/6 mice (Charles River Laboratories, Wilmington, MA) were maintained on 12-hour light-dark cycles with ad libitum standard food and water. Within 24 hours of birth, litters were pooled and randomized into exposure groups. Paired with a nursing dam, pups were raised in $60 \%$ oxygen or room air (21\%) for 21 days. Hyperoxia-exposed animals were housed in standard cages placed in a 38-L Plexiglas chamber with a continuous flow of blended oxygen $(2 \mathrm{~L} / \mathrm{min})$. Oxygen concentrations were monitored twice daily via an oxygen analyzer (miniOX I; MSA Medical, Gurnee, IL). To control for oxygen exposures, nursing dams were rotated between paired litters during weekly cage changes. Ventilator studies were conducted and/or tissue harvested within 24 hours of removal from hyperoxia at 3 weeks. A subgroup of animals was returned to room air following 3 weeks of initial hyperoxia exposure and subsequently recovered to 6 weeks of age for adult lung mechanic and GSNOR activity studies.

GSNOR Activity by Copper Cysteine Reagent and Nitric Oxide Analysis. Enzyme activity in lung homogenates from 3-weekold and 6-week-old mice was assessed by timed GSNO catabolism (Brown-Steinke et al., 2010) and quantification by copper-cysteine reagent and nitric oxide analysis (2C/NOA). After terminal anesthesia with i.p. ketamine/xylazine (Pfizer, St. Joseph, MO; Lloyd Laboratories, Shenandoah, IA), lungs from mice were harvested and rinsed in ice-cold phosphate-buffered saline (PBS, $\mathrm{pH}$ 7.4), placed in centrifuge tubes, snap-frozen in liquid nitrogen, and stored at $-80^{\circ} \mathrm{C}$. Tissue in ice-cold radioimmunoprecipitation assay lysis buffer containing protease inhibitors (Santa Cruz Biotechnology, Dallas, TX) was homogenized, and protein levels were quantified by Pierce bicinchoninic acid (BCA) protein assay kit (Thermo Scientific, Waltham, MA). A known quantity of GSNO $(28 \mu \mathrm{M})$ was loaded with coreagents $(300 \mu \mathrm{M} \mathrm{NADH}$ and $2 \mathrm{mM}$ glutathione; Sigma-Aldrich, St. Louis, MO) and equivalent protein quantities of frozen lung homogenates in PBS. After incubation for 5 minutes at $37^{\circ} \mathrm{C}$, the reaction was quenched by a $1: 10$ dilution of ice-cold PBS. Uncatabolized GSNO was then measured by 2C/NOA, as previously described in detail (Rogers et al., 2013). Briefly, samples were injected into a temperature-controlled reservoir containing copper cysteine reagent $(\mathrm{pH}<6.9)$ with a continuous flow of blended helium. Gas-phase nitric oxide was liberated from GSNO contained in the injected samples and detected by ozone-based chemiluminescence using an inline nitric oxide analyzer (Seivers 280i; GE Instruments, Boulder, CO). GSNO content was determined by fitting chemiluminescence peaks to a GSNO standard curve and normalizing to sample protein levels. Enzyme kinetics were further derived from a Lineweaver-Burke double-reciprocal plot utilizing a total of three loading doses of GSNO (14, 28, and $56 \mu \mathrm{M})$.

Western Blot. Harvested snap-frozen lungs from 3-week-old mice were homogenized in ice-cold radioimmunoprecipitation assay lysis buffer containing protease inhibitors (Santa Cruz Biotechnology), and protein levels were determined by BCA assay (Thermo Scientific). Samples of $50 \mu \mathrm{g}$ protein were separated by electrophoresis with 415\% Mini Protean TGX precast gels (Bio-Rad Laboratories, Hercules, $\mathrm{CA}$ ) and transferred to nitrocellulose membranes (P:0 on iBlot; Invitrogen, Rehovot, Israel). Membranes were blocked with 5\% milk or bovine serum albumin (BSA; Sigma-Aldrich) and incubated in GSNOR primary antibody (1:1000 in milk; observed band $40 \mathrm{kDa}$; Proteintech, Rosemont, IL), endothelial NOS primary antibody (1: 1000 in BSA; observed band $140 \mathrm{kDa}$; BD Transduction Laboratory, San Jose, CA), iNOS primary antibody (1:1000 in BSA; observed band $145 \mathrm{kDa}$, Abcam, Cambridge, MA), or neuronal NOS primary antibody (1:500 in milk; expected band $161 \mathrm{kDa}$; Abcam) overnight at $4^{\circ} \mathrm{C}$ and then horseradish peroxidase-conjugated secondary anti-rabbit antibody (1:3000; Santa Cruz, Dallas, TX) or anti-mouse antibody (1:3000; Santa Cruz), as appropriate, for 1 hour at room temperature. As a loading control, membranes were stripped (Pierce Restore; Thermo Scientific) and reprobed with $\beta$-actin primary antibody (1:2000 in milk; observed band $42 \mathrm{kDa}$, Abcam) and anti-mouse horseradish peroxidase-conjugated secondary antibody (1:5000; Abcam). Band intensities were quantified and normalized to $\beta$-actin using Super Signal West Pico Chemiluminescent Substrate (Thermo Scientific). Relative intensities were measured using densitometry software (Image J, NIH).

Immunohistochemistry. After terminal anesthesia (ketamine/xylazine), lungs of 3-week-old mice were inflated with intratracheal $10 \%$ formalin at $25 \mathrm{~cm} \mathrm{H}_{2} \mathrm{O}$; tissue was saline perfused with $\mathrm{PBS}$ ( $\mathrm{pH}$ 7.4) and then formalin. The right lung was postfixed in $10 \%$ formalin 
at $4^{\circ} \mathrm{C}$ for $>24$ hours, tissue was paraffin embedded, and $5-\mu \mathrm{m}-$ cut sections were processed. Tissue sections were immunoblotted with GSNOR primary antibody (1:200; Proteintech) at $4^{\circ} \mathrm{C}$ overnight and then biotinylated goat anti-rabbit secondary antibody (1:10,000; Vector Laboratories, Burlingame, CA) using Vectastain ABC kit, and next counterstained with methylene blue (Sigma-Aldrich), as previously described (Marozkina et al., 2012). Primary antibody was omitted as a negative control. Airways were similarly imaged (Rolera XR CCD camera; Q Imaging, Surrey, Canada).

miR Microarray. RNA was extracted from saline-perfused snapfrozen lungs of 3-week-old mice preserved in RNAlater-ICE reagent using a miRVana column isolation kit (Life Technologies, Carlsbad, CA). RNA was quantified by Nanodrop spectroscopy (Thermo Scientific), and microarray analysis of all mature mouse probes from the miRBase V21 library were compared between groups (LC Sciences, Houston, TX). Utilizing a gene-miR interaction search (Dweep et al., 2011, 2014) for the $3^{\prime}$ untranslated region binding site of GSNOR mRNA (gene id: $a d h 5$, alcohol dehydrogenase 5), the most predicted miR candidates were cross-referenced with the microarray results, and high-probability miRs were selected and confirmed by quantitative reverse-transcription polymerase chain reaction (qRT-PCR).

qRT-PCR. RNA was extracted from frozen lungs of 3-week-old mice using TRIzol reagent (Life Technologies) and quantified by Nanodrop spectroscopy (Thermo Scientific). cDNA was generated from $1 \mu \mathrm{g}$ RNA by reverse transcription using qScript $\mathrm{cDNA}$ synthesis kit (Quanta Biosciences, Gaithersburg, MD). Real-time quantitative polymerase chain reaction was performed on a StepOne PCR system (Applied Biosystems, Foster City, CA) using TaqMan probes (Life Technologies) for GSNOR (Mm00475804_g1) compared with 25\% diluted $\beta$-actin control (Thermo Scientific) with PerfeCTa qPCR FastMix, UNG, ROX (Quanta Biosciences, Gaithersburg, MD). For microRNA qRT-PCR, RNA was similarly extracted as in the miR microarray studies. cDNA was generated using TaqMan primerspecific assays and MicroRNA Reverse Transcription kit, and realtime quantitative polymerase chain reaction was performed using TaqMan MicroRNA assays for microRNA-342-3p (2260, Thermo Scientific) compared with snRNA-U6 control (001973, Thermo Scientific) with TaqMan Universal Master Mix, No AmpErase UNG (Life Technologies). Fold changes are reported utilizing $2^{\wedge}$-ddCT method and StepOne software v2.3 (Applied Biosystems).

Transfection with mmu-miR-342-3p and Cytomix Activation of RAW 264.7 Cells. RAW 264.7 macrophage cells (American Type Culture Collection, Manassas, VA) were cultured in Gibco Dulbecco's modified Eagle's medium with 10\% fetal bovine serum and 1\% penicillin-streptomycin (Life Technologies). Cells were transfected with $20 \mathrm{nM}$ miRIDIAN miR mimic for mmu-miR-342-3p or with a miR mimic transfection control, cel-miR-67 (Dharmacon, GE Lifesciences, Lafayette, CO) by AMAXA electroporation utilizing Nucleofector Kit V (Lonza Group, Basel, Switzerland), per manufacturer's instructions. After 48 hours, cells were harvested for protein or RNA studies, and pellets were snap frozen. Protein levels were determined by BCA assay, and protein was equivalently loaded for gel electrophoresis and Western blot analysis of GSNOR: $\beta$-actin, as described above. RAW 264.7 qRT-PCR for miR-342-3p was similarly performed on transfected cells, as described above, to confirm increased gene expression resulting from transfection. Additionally, untransfected RAW 264.7 cells in culture media were incubated with cytomix (10 ng/mL each interleukin- $1 \beta$, tumor necrosis factor- $\alpha$, interferon- $\gamma$, and lipopolysaccharide; Sigma-Aldrich) or vehicle for 10 hours to measure changes in GSNOR expression in the activated macrophage (Tan et al., 2013).

Synthesis of GSNO. GSNO was synthesized in-house adapted from a protocol, as previously published (Hart, 1985). Using a nitrogen sparge at $4^{\circ} \mathrm{C}$ in light-protective conditions, reduced L-glutathione $(2 \mathrm{~g})$ in purged hydrochloric acid $(2 \mathrm{~N})$ and purged ultrapure water was S-nitrosylated with sodium nitrite $(455 \mathrm{mg}$ ) over $30-60$ minutes (Sigma-Aldrich). The resulting pink GSNO solution was vacuum filtered, mixed with $10 \mathrm{~mL}$ purged 50\% acetone for 10-20 minutes, and filtered again. Samples were lyophilized and stored at $-80^{\circ} \mathrm{C}$. Concentration was confirmed by Saville assay (Gaston et al, 1994).

GSNOR Inhibitor Administration. N6022 is a selective smallmolecule reversible inhibitor of GSNOR (Green et al., 2012; Blonder et al., 2014). Powdered N6022 (Nivalis Therapeutics, Boulder, CO, purchased through MedChem Express, Monmouth Junction, $\mathrm{NJ}$ ) was reconstituted in sterile PBS ( $\mathrm{pH}$ 7.4) and administered to hyperoxiaexposed mice as a single $1 \mathrm{mg} / \mathrm{kg}$ i.p. injection the day prior to testing lung mechanics. Dosage was chosen based upon the published work of Blonder et al. (2014).

Lung Mechanics. Under general anesthesia (i.p. ketamine/xylazine), mice were placed supine on a heated surgical table, tracheostomized, and ventilated via a 19-gauge blunt-tip cannula with a commercial rodent ventilator (flexiVent; SCIREQ, Montreal, Canada). Animals were paralyzed (i.p. pancuronium bromide; Sigma-Aldrich) and ventilated at default settings: tidal volume of $10 \mathrm{~mL} / \mathrm{kg}$, a rate of $150 \mathrm{breaths} / \mathrm{min}$, a positive end expiratory pressure of $3 \mathrm{~cm} \mathrm{H}_{2} \mathrm{O}$, and a $\mathrm{FiO}_{2}$ of $50 \%$. Following two recruitment deep inflations of sustained inspiration up to a pressure of $30 \mathrm{~cm} \mathrm{H}_{2} \mathrm{O}$ for 3 seconds, $10 \mathrm{mM}$ GSNO or saline vehicle was aerosolized over 10 seconds using an ultrasonic nebulizer (Aeroneb; SCIREQ) diverted into the ventilator's inspiratory flow. Inhaled GSNO concentration was chosen based upon the published studies in ventilated guinea pigs (Bannenberg et al., 1995) and human trials in cystic fibrosis (Snyder et al., 2002). After 5 minutes had elapsed, two recruitment deep inflations were again delivered, and increasing methacholine doses of $0,12.5,25,50,100$, and $200 \mathrm{mg} / \mathrm{mL}$ were similarly aerosolized over 10 seconds to generate a dose-response curve. Using computer software (flexiWare 5.1, Version 7.2, SCIREQ), five measurements of respiratory system resistance (Rrs) were calculated by a $2.5 \mathrm{~Hz}$ single-frequency forced oscillation maneuver (Snapshot 150) (Shalaby et al., 2010), and an average was reported for each methacholine dose. Respiratory mechanics were measured in both 3 -week-old mice immediately following sustained hyperoxia exposure and separate 6 -week-old mice that were recovered in room air following the initial 3 weeks of hyperoxia exposure.

Statistics. Data are expressed as means \pm S.E.M. A minimum of two litters or experiments was used for each study; $n$ represent individual animals or cell transfections. Data containing two groups were first tested for normality and variance and then analyzed by twosample Student $t$ test, Welch's $t$ test, or Mann-Whitney $U$ test, as appropriate. For multiple comparisons, analysis of variance with Tukey-Kramer post hoc test was used. Alterations in airway reactivity with increasing doses of methacholine were compared by two-way analysis of variance repeated-measures analysis with Tukey-Kramer post hoc comparisons using a fixed-sequence method from highest to lowest methacholine dose. $P<0.05$ was considered statistically significant.

Materials. If not otherwise stated, all reagents and chemicals were purchased from Sigma-Aldrich and were of an analytical grade.

\section{Results}

GSNO Catabolism Is Increased after Neonatal Hyperoxia. As described in asthma, increased expression of GSNOR causes loss of the endogenous bronchodilator, GSNO, and increased bronchial hyperreactivity (Fang et al., 2000; Que et al., 2009). Using 2C/NOA, we have shown that GSNOR activity (NADH-dependent GSNO catabolism $/ \mathrm{min} / \mathrm{mg}$ protein) in the lungs of 3-week-old mice raised in neonatal hyperoxia was higher than that of room air controls (Fig. 1A). The Lineweaver-Burke plots of estimated maximum velocity and Michaelis-Menton constant tended to be increased among the hyperoxia-exposed group (Fig. 1B), yet the ratio of maximum velocity/Michaelis-Menton constant was similar between groups. Although these kinetic findings could indicate loss of 


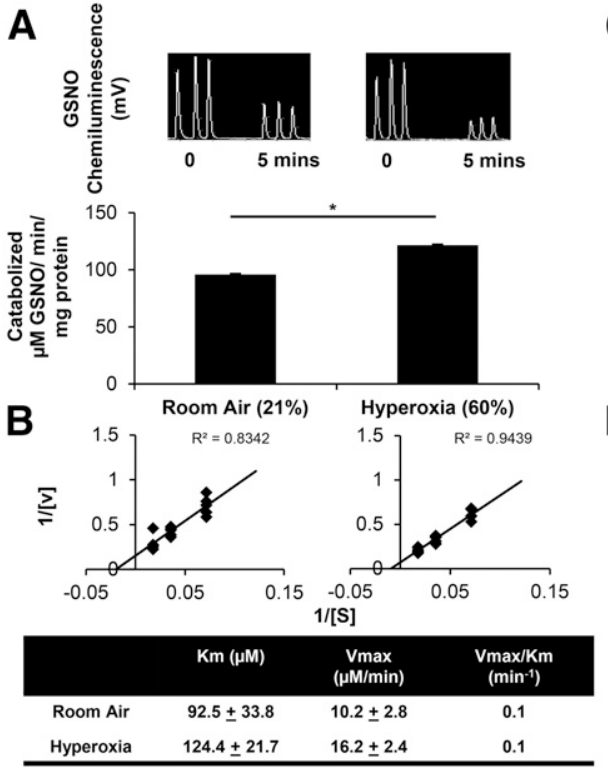

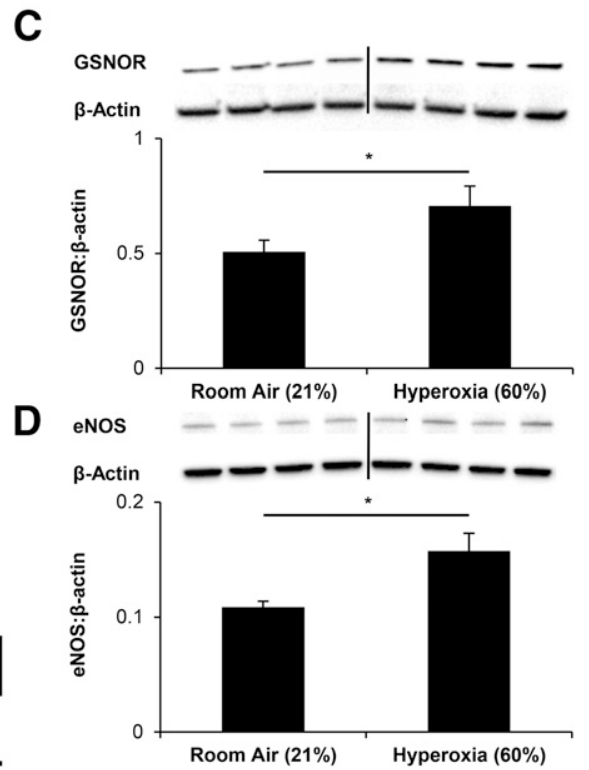

Fig. 1. Increased GSNOR activity and expression in 3-week-old mice after neonatal hyperoxia exposure. (A) GSNOR activity was assessed by timed GSNO catabolism in lung homogenates, normalized to protein. GSNOR activity was increased in hyperoxia. Representative nitric oxide analyzer tracings in triplicate are shown. Data were normally distributed with equal variance, so a two-tailed Student $t$ test was used. $n=5$. $* P<$ 0.05. (B) GSNOR kinetics were estimated by generating a Lineweaver-Burke plot at differing GSNO substrate loads. Maximum velocity/Michaelis-Menton constant did not differ between groups. Data were normally distributed with equal variance, so a two-tailed Student $t$ test was used. $n=5$. (C) Representative Western blot bands from the same gel are shown. Relative expression of GSNOR: $\beta$-actin ratio was increased in hyperoxia. Data were normally distributed with unequal variance, so a two-tailed Welch's $t$ test was used. $n=12$. ${ }^{*} P<0.05$. (D) Representative Western blot bands from the same gel are shown. Relative expression of eNOS: $\beta$-actin was increased in hyperoxia. Data were normally distributed with equal variance, so a two-tailed Student $t$ test was used. $n=4$. $* P<0.05$. a noncompetitive inhibitor, the most likely explanation was increased GSNOR expression in hyperoxia. GSNOR activity was also measured by $2 \mathrm{C} / \mathrm{NOA}$ in the lung homogenates from 6 -week-old mice who were exposed to 3 weeks of hyperoxia and then recovered in room air. GSNOR activity remained significantly increased in the hyperoxia-exposed room air-recovered mice, compared with 6-week-old room air controls (11.84 \pm 0.22 versus $11.08 \pm 0.17 \mu \mathrm{M} / \mathrm{min} / \mathrm{mg}$ protein, respectively, $P<0.05$ ), albeit with less catabolic activity per mg protein than at 3 weeks of age.

GSNOR Expression Is Increased after Neonatal Hyperoxia. Consistent with the GSNOR kinetic data in 3 -week-old mice, the relative protein expression of GSNOR was increased in the lungs of 3 -week-old mice raised in hyperoxia when compared with room air controls, as assessed by Western blot (Fig. 1C).

eNOS Expression Is Increased after Neonatal Hyperoxia. The relative protein expression of eNOS was increased in the lungs of 3 -week-old mice raised in hyperoxia when compared with room air controls, as assessed by Western blot (Fig. 1D). iNOS expression was not significantly different between groups, and neuronal NOS was not detected in the lungs of either group by this Western blot preparation (data not shown).

GSNOR Gene Expression Is Not Increased after Neonatal Hyperoxia. To determine whether differences in GSNOR expression were transcriptionally mediated, we performed qRT-PCR on lung homogenates from 3-week-old mice raised in hyperoxia or room air. GSNOR mRNA expression did not differ between groups.

GSNOR Immunohistochemistry. GSNOR immunostaining was prominent in the hyperoxia-exposed 3-week-old mice and, consistent with previous findings (Marozkina et al., 2012, 2015), staining was localized to the epithelium and smooth muscle of the airways (Fig. 2).

mmu-miR-342-3p Gene Expression Is Decreased after Neonatal Hyperoxia. Because GSNOR mRNA expression did not explain differences in GSNOR protein expression, we next investigated whether microRNA gene silencing regulates its expression. Microarray analysis performed on lung homogenates from individual 3-week-old animals identified miR candidates found to have decreased expression in hyperoxia. MicroRNA candidates were then cross-referenced with the highest predicted gene-miR interactions to adh5, the GSNOR gene (Fig. 3A). mmu-miR-342-3p showed trends toward decreased expression in hyperoxia by microarray and
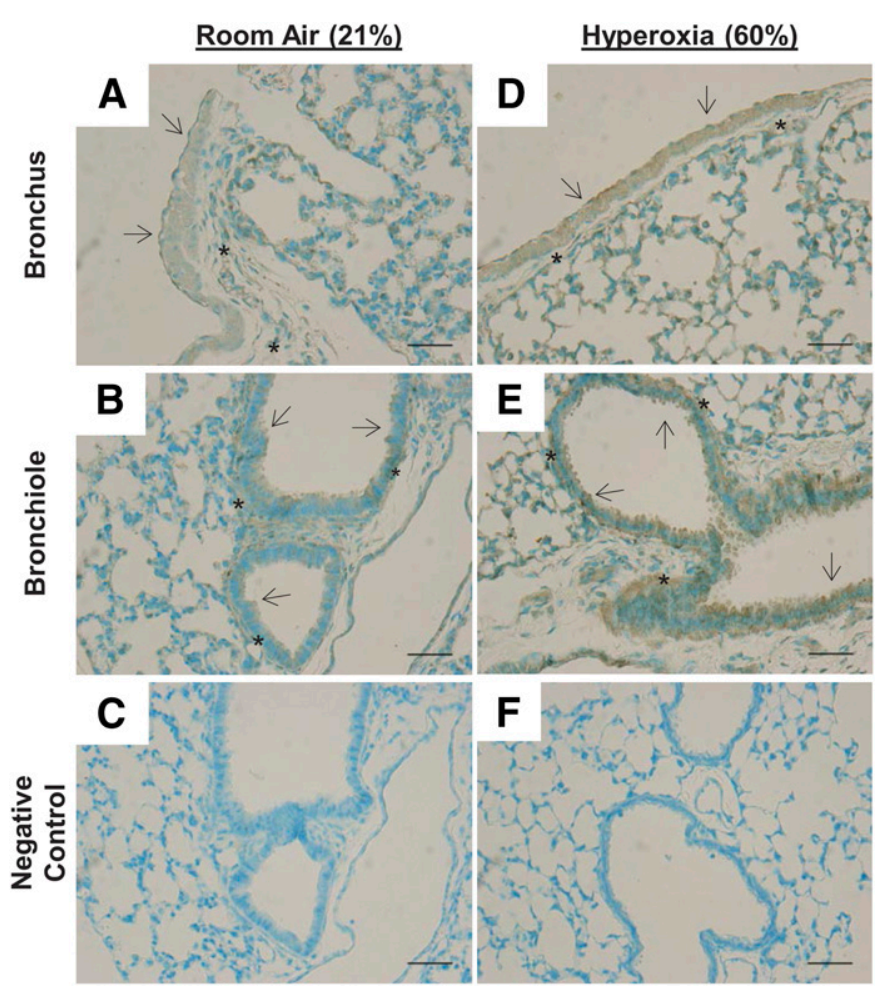

Fig. 2. GSNOR immunostaining following hyperoxia in lungs of 3-weekold mice. Representative immunohistochemical probe for GSNOR (brown) of inflation-fixed lung sections showed prominent staining of airway epithelium (arrows) and smooth muscle (*) in the bronchus (A, D) and bronchioles (B, E) of both groups. Sections were counterstained with methylene blue. Primary antibody was omitted as a negative control (C, F). Scale bar $=50 \mu \mathrm{m}$. 



B

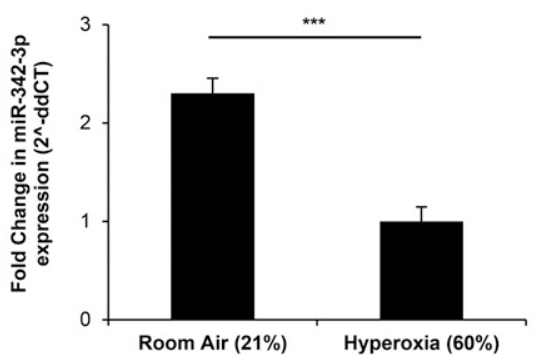

C

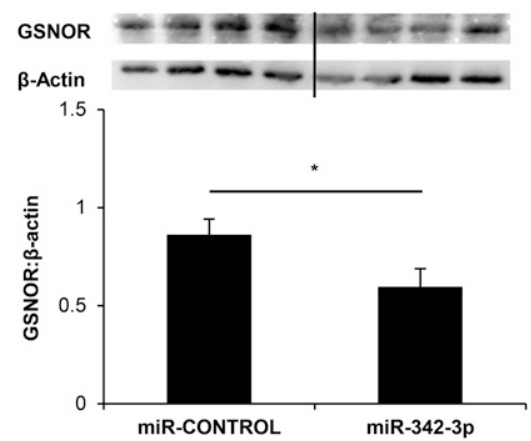

Fig. 3. microRNA-342-3p regulates post-transcriptional expression of GSNOR. (A) Approach for identifying miR candidates most likely to interact with GSNOR post-transcriptional expression. miR candidates that displayed decreased expression in hyperoxia by microarray analysis were identified. Candidates were then cross-referenced with the highest predicted GSNOR gene-miR interactions using results of multiple prediction algorithms. miR-342-3p had trends toward decreased expression in hyperoxia by microarray analysis $(n=2)$ and was highly predicted to interact with GSNOR mRNA $(6$ of 10 prediction algorithms). (B) qRT-PCR was performed on lung homogenates from 3-week-old mouse pups to confirm significant changes in miR-342-3p expression. Fold decreases in miR-342-3p expression were observed in hyperoxia compared with room air controls. Data were normally distributed with equal variance, so a two-tailed Student $t$ test was used. $n=6$. ${ }^{* * *} P<0.001$. (C) Mouse macrophage RAW 264.7 cells were transiently transfected with a miR-342-3p mimic or a miR mimic control (cel-miR-67) to assess miR silencing of GSNOR protein expression. Western blot analysis for GSNOR was performed on lysed cells 48 hours after transfection. Representative Western blot bands from the same gel are shown. Relative expression of GSNOR: $\beta$-actin ratio was decreased in cells overexpressing miR-342-3p. Data were normally distributed with equal variance, so a two-tailed Student $t$ test was used. $n=8$. ${ }^{*} P<0.05$.

was predicted by six different prediction data sets to interact with the $3^{\prime}$ untranslated region of GSNOR (Dweep et al., 2011, 2014). mmu-miR-342-3p was confirmed by qRT-PCR to be significantly underexpressed in the lungs of hyperoxiaexposed 3-week-old mice when compared with room air controls (Fig. 3B).

Transfection with miR-342-3p Decreases GSNOR Expression. We next showed that miR-342-3p decreases protein expression of GSNOR using mouse macrophage RAW 264.7 cells. RAW 264.7 cells endogenously express GSNOR (confirmed by Western blot in naive cells and those activated with cytomix; no significant difference was observed with cytomix treatment) and were one of the original cell lines used to isolate and describe GSNOR (Liu et al., 2001). RAW 264.7 cells transiently transfected with a miR-342-3p mimic had decreased GSNOR protein expression compared with cells transfected with a miR mimic control (Fig. 3C). We confirmed miR-342-3p overexpression following transfection by qRT-PCR.

Hyperoxic Changes in Respiratory Mechanics Are Attenuated by Pretreatment with a GSNO Aerosol or by GSNOR Inhibition. We have shown that neonatal hyperoxia increased GSNOR activity and expression. Therefore, we tested whether GSNO repletion or GSNOR inhibition could reverse the airway hyperreactivity observed in our BPD model. Responses to methacholine-provoked airway hyperresponsiveness were characterized by measuring Rrs, an indicator of airway hyperreactivity. Compared with room air controls, 3-week-old mice raised in hyperoxia displayed elevated Rrs in response to aerosolized methacholine challenge (Fig. 4A). Pretreatment of the hyperoxia-exposed mice with a 10-second GSNO aerosol attenuated these changes, such that this group was no longer significantly different from room air controls, except at the highest methacholine dose $(200 \mathrm{mg} / \mathrm{mL})$. Pretreatment of the hyperoxia-exposed mice with an i.p. injection of a selective inhibitor of GSNOR activity, N6022 (Green et al., 2012), attenuated these changes as well, such that this group was no longer significantly different from room air controls at all methacholine doses. Next we show in room air-recovered six-week-old animals that neonatal hyperoxia-exposed mice continued to have elevated Rrs in response to aerosolized methacholine challenge when compared with room air-raised controls (Fig. 4B). In these six-week-old mice exposed to neonatal hyperoxia, both pretreatment with GSNO aerosolization and GSNOR inhibition with N6022 remained effective in attenuating the hyperoxiainduced airway hyperresponsiveness. At both ages, pretreatment with GSNO in room air-exposed mice did not significantly change Rrs when compared with room air saline-treated controls (data not shown), and baseline Rrs prior to aerosolizations was not statistically different between groups (data not shown).

\section{Discussion}

In this neonatal mouse model of $\mathrm{BPD}$, hyperoxia exposure was associated with increased GSNO catabolism through increased lung expression of GSNOR. Hyperoxia exposure also increased expression of lung eNOS, which has been shown to increase activity, but not protein expression of GSNOR in adult models. We have shown that one mechanism for 


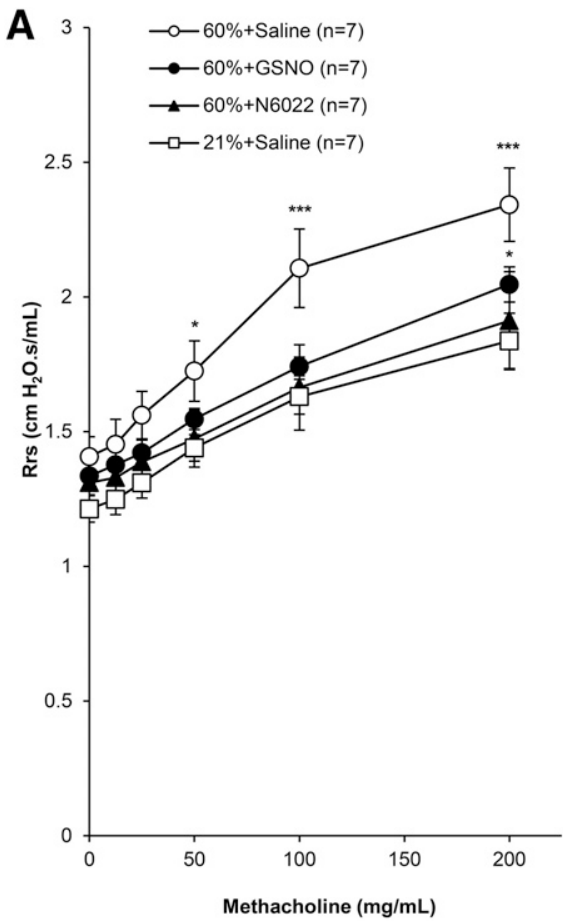

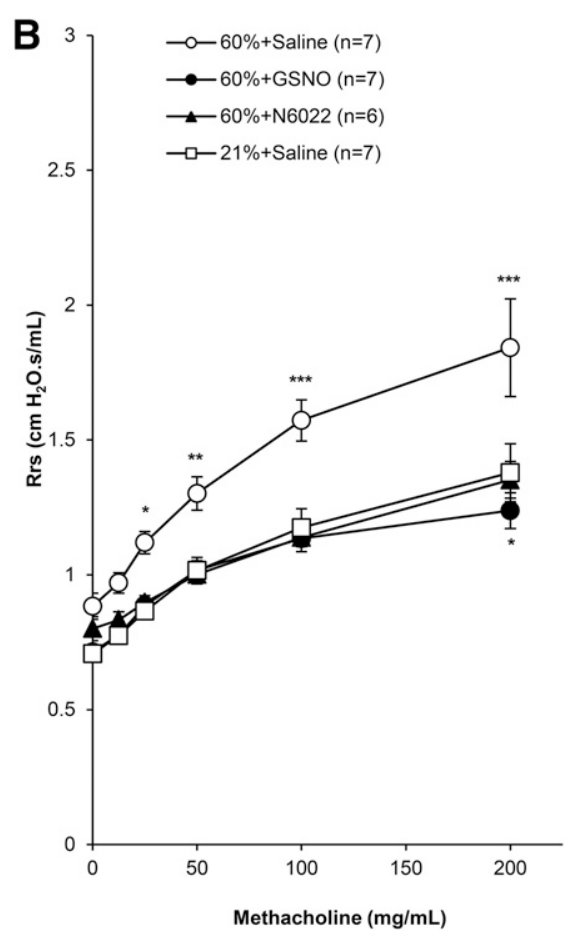

Fig. 4. GSNO aerosol or GSNOR inhibition attenuates hyperoxia-induced airway hyperresponsiveness to methacholine challenge. Aerosolized methacholine dose responses were compared in (A) 3-week-old mouse pups raised from birth in room air $(21 \%)$ or hyperoxia $(60 \%)$ and in (B) adult 6-week-old mice raised in room air or recovered in room air after the initial 3-week hyperoxia exposure. Mice were pretreated with saline vehicle aerosol, $10 \mathrm{mM}$ GSNO aerosol, or $1 \mathrm{mg} / \mathrm{kg}$ N6022 GSNOR inhibitor injection. Rrs was significantly increased in hyperoxia at 3 weeks and after room air recovery at 6 weeks of age; pretreatment with GSNO or N6022 attenuated these changes. Comparisons were made to $21 \%$ + saline control. Two-way analysis of variance with fixed sequence TukeyKramer post hoc analysis from highest to lowest methacholine dose was used. $* P<$ $0.05, * * P<0.01, * * * P<0.001$. hyperoxia-induced upregulation of GSNOR protein expression is through altered post-transcriptional regulation by miR-342$3 \mathrm{p}$; we anticipate that this mechanism may be relevant to other pulmonary toxicities associated with hyperoxia exposure. As anticipated, neonatal hyperoxia increased methacholine-induced airway hyperresponsiveness in both juvenile mice immediately following hyperoxia exposure and room air-recovered adult mice. Remarkably, these detrimental changes in respiratory mechanics were attenuated at both ages by supplementation with a single dose of exogenous GSNO or by administration of a GSNOR inhibitor. These data indicate that GSNOR is an important modulator of neonatal hyperoxia-induced airways reactivity and that it may be a promising new drug target for BPD treatment.

The most immediate respiratory complication following premature birth is respiratory distress syndrome. Newborns with this condition frequently require oxygen supplementation (Carlo et al., 2010), yet this life-saving intervention increases the infant's risk for developing longer-term respiratory morbidities such as BPD (Laughon et al., 2011) and childhood wheezing (Grischkan et al., 2004; Halvorsen et al., 2005; Stevens et al., 2010). In our murine model, moderate hyperoxia elicited increased airway hyperresponsiveness, consistent with other models of moderate hyperoxia $\left(\mathrm{FiO}_{2}\right.$ 40-70\%) in newborn rodents (Takeda et al., 2009; Wang et al., 2014). Moderate neonatal hyperoxia ( $65 \%$ for just 7 days) may cause lasting changes in bronchiolar smooth muscle, alveolar attachments, and airway tethering, potentially predisposing adult mice to increased airways reactivity (O'Reilly et al., 2014). We show in this work that GSNO-based treatments reverse hyperoxia-induced airway hyperresponsiveness in both juvenile and adult BPD mice. In the room airrecovered BPD adult mouse, elevated GSNOR activity is somewhat attenuated, yet GSNO and GSNOR inhibition remain effective therapies in attenuating airway hyperreactivity. We speculate that GSNO's protective effects on airway hyperreactivity may persist well into adulthood and need to be studied further.

GSNO and GSNOR inhibition has been shown by our group and others to relax airway smooth muscle and attenuate methacholine-induced bronchoconstriction through a variety of tested pathways. GSNO acts in both a cGMP-dependent soluble guanylate cyclase/protein kinase $\mathrm{G}$ pathway (Mayer et al., 1998) and a cGMP-independent manner via GSNOmediated S-nitrosylation of intracellular Cys thiols that relaxes airway smooth muscle and is reversed by the thiolreducing agent DL-dithiothreitol (Perkins et al., 1998). GSNO decreases calcium sensitivity of airway smooth muscle, thus reducing regulatory myosin light chain phosphorylation (Pabelick et al., 2000); and striated muscle myosin heavy chains have been shown to be S-nitrosylated in vivo (Evangelista et al., 2010). Additionally, SNOs alleviate bronchoconstriction through cGMP-independent activation of the voltage- and calcium-dependent potassium (BK) channels (Abderrahmane et al., 1998; Janssen et al., 2000) and inhibition of the ADP-ribose cyclase activity of CD38 (White et al., 2002). Pathways relevant in neonatal hyperoxia induced smooth muscle reactivity (Mhanna et al., 2004; Smith et al., 2007; Sopi et al., 2007; Ali et al., 2012; Britt et al., 2015).

In a rodent model of severe neonatal hyperoxia, continuous treatment with an S-nitrosylating gas, ethyl nitrite, improved lung compliance, decreased inflammation, and promoted lung development (Auten et al., 2007). Note that ethyl nitrite inhalation leads to S-nitrosothiol production in vivo (Moya et al., 2001); our current data regarding elevated GSNOR activity in neonatal hyperoxia and potential benefits of GSNO repletion may help to explain these previous results. Additionally, GSNO can improve vascular development (Lima et al., 2009), which could also be of benefit to patients with BPD (Thébaud and Abman, 2007). As such, chronic GSNO repletion on lung parenchymal and vascular development following neonatal hyperoxia may be important to investigate. 
Although the phenotype has evolved (Baraldi and Filippone, 2007; Jobe, 2011) since Northway et al. (1967) first described BPD five decades ago, little has changed in symptomatic therapies for the persistent breathing problems experienced by these survivors of premature birth (Allen et al., 2003; Iyengar and Davis, 2015). Despite transient bronchodilation with $\beta 2$-adrenergic agonists (Gomez-Del Rio et al., 1986; Wilkie and Bryan, 1987), premature survivors show variable responses (Yuksel and Greenough, 1993; De Boeck et al., 1998; Baraldi et al., 2005), and chronic therapy with these agents potentially creates tolerance (Motoyama et al., 1987; Subbarao and Ratjen, 2006) without decreasing the incidence of BPD (Denjean et al., 1998). This may reflect tachyphylaxis caused by loss of $\beta 2$-adrenergic receptors in experimental BPD (Raffay et al., 2014). In both pulmonary and myocardial models, S-nitrosothiols protect against this tachyphylaxis (Whalen et al., 2007). Specifically, in both cases, loss of the GSNO catabolic enzyme, GSNOR, is protective. We speculate that GSNO-based therapies may have additional benefits in BPD through attenuating $\beta 2$-adrenergic receptor desensitization.

To our knowledge, this is the first demonstration that elevated GSNOR content and activity contribute to neonatal hyperoxic increases in airway hyperresponsiveness. GSNOR has been studied extensively in clinical and experimental asthma, cystic fibrosis, and pulmonary hypertension. It has been observed that transgenic mice unable to express GSNOR are protected from ovalbumin-induced asthmatic reactivity (Que et al., 2005). Treatments with GSNOR inhibitors (Ferrini et al., 2013; Blonder et al., 2014) have likewise been shown to be protective of adult murine asthmatic hyperreactivity. Asthma patients with respiratory failure are depleted of airway GSNO (Gaston et al., 1998), and those with elevated GSNOR have more severe airways reactivity and earlier onset of symptoms (Que et al., 2009; Marozkina et al., 2015). Cystic fibrosis patients have decreased airway levels of GSNO (Grasemann et al., 1999) and show improved oxygenation when administered exogenous GSNO (Snyder et al., 2002); as such, pharmacologic GSNOR inhibition is undergoing clinical investigation as a cystic fibrosis treatment (Tait and Miller, 2014). Lastly, infants with persistent pulmonary hypertension of the newborn have shown improved oxygenation after administration of a gaseous S-nitrosylating agent (Moya et al., 2002). These studies suggest that GSNOR is, in general, an important modulator of various conditions of pulmonary stress.

In this study, we describe a novel mechanism of dysregulated post-transcriptional GSNOR protein expression via miR silencing. Although eNOS expression has been shown to increase the catabolic activity of GSNOR (Brown-Steinke et al., 2010), GSNOR protein expression remained unchanged. The elevated eNOS expression in association with hyperoxia exposure shown here - and previously by our group (Potter et al., 1999) - does not fully explain the observed kinetics, protein, and immunostaining for GSNOR. MicroRNAs are small, noncoding RNAs that function through complementary binding to target sequences in mRNA. This interferes with translation, resulting in decreased protein expression (Bhaskaran and Mohan, 2014). As previously described in a different hyperoxic BPD model (Bhaskaran et al., 2012), we also observed decreased expression of miR-342-3p in the mouse cohort that was exposed to hyperoxia. This miR was highly predicted to interact with GSNOR mRNA and, indeed, in vitro overexpression of miR-342-3p resulted in decreased GSNOR protein levels. Although control of protein expression under conditions of hyperoxia is multifactorial, altered miR post-transcriptional regulation is a compelling epigenetic mechanism by which GSNOR can be regulated. Future in vivo studies of miR-342-3p are important to further the understanding of the miR's role in neonatal hyperoxia.

Despite their widespread use in premature infants and children (Mhanna et al., 2009; Slaughter et al., 2014, 2015), limited evidence exists for the efficacy of asthma therapies, such as inhaled corticosteroids (Pelkonen et al., 2001; Gupta et al., 2012) and bronchodilators (Pantalitschka and Poets, 2006; Ng et al., 2012). Furthermore, there is a paucity of recommendations for the adult management of this growing patient population (Bolton et al., 2015). Targeted replacement of depleted GSNO stores in the developing lung exposed to hyperoxia, directly or through inhibition of GSNOR, may provide an exciting new treatment modality for this high-risk population of infants and children.

\section{Acknowledgments}

The authors thank Dr. Tracey Bonfield for provision of RAW 264.7 cells, Dr. Stephen Lewis for insightful advice on the manuscript, and the technical support of Catherine Mayer, Maureen O'Reilly, Christiaan Wijers, and Dr. Christopher Nitkin.

\section{Authorship Contributions}

Participated in research design: Raffay, Khalil, MacFarlane, Martin, Gaston.

Conducted experiments: Raffay, Dylag, Smith, Einisman, Li, Lakner.

Contributed new reagents or analytic tools: Dylag.

Performed data analysis: Di Fiore.

Wrote or contributed to the writing of the manuscript: Raffay, Gaston.

\section{References}

Abderrahmane A, Salvail D, Dumoulin M, Garon J, Cadieux A, and Rousseau E (1998) Direct activation of K(Ca) channel in airway smooth muscle by nitric oxide: involvement of a nitrothiosylation mechanism? Am J Respir Cell Mol Biol 19: $485-497$

Ali NK, Jafri A, Sopi RB, Prakash YS, Martin RJ, and Zaidi SI (2012) Role of arginase in impairing relaxation of lung parenchyma of hyperoxia-exposed neonatal rats. Neonatology 101:106-115.

Allen J, Zwerdling R, Ehrenkranz R, Gaultier C, Geggel R, Greenough A, Kleinman R, Klijanowicz A, Martinez F, Ozdemir A, et al.; American Thoracic Society (2003) Statement on the care of the child with chronic lung disease of infancy and childhood. Am J Respir Crit Care Med 168:356-396.

Amy RW, Bowes D, Burri PH, Haines J, and Thurlbeck WM (1977) Postnatal growth of the mouse lung. J Anat 124:131-151.

Auten RL, Mason SN, Whorton MH, Lampe WR, Foster WM, Goldberg RN, Li B, Stamler JS, and Auten KM (2007) Inhaled ethyl nitrite prevents hyperoxiaimpaired postnatal alveolar development in newborn rats. Am J Respir Crit Care Med 176:291-299.

Bannenberg G, Xue J, Engman L, Cotgreave I, Moldéus P, and Ryrfeldt A (1995) Characterization of bronchodilator effects and fate of S-nitrosothiols in the isolated perfused and ventilated guinea pig lung. J Pharmacol Exp Ther 272:1238-1245.

Baraldi E, Bonetto G, Zacchello F, and Filippone M (2005) Low exhaled nitric oxide in school-age children with bronchopulmonary dysplasia and airflow limitation. Am J Respir Crit Care Med 171:68-72.

Baraldi E, Carraro S, and Filippone M (2009) Bronchopulmonary dysplasia: definitions and long-term respiratory outcome. Early Hum Dev 85:S1-S3.

Baraldi E and Filippone M (2007) Chronic lung disease after premature birth. N Engl J Med 357:1946-1955.

Berger J and Bhandari V (2014) Animal models of bronchopulmonary dysplasia: the term mouse models. Am J Physiol Lung Cell Mol Physiol 307:L936-L947.

Bhandari V, Choo-Wing R, Chapoval SP, Lee CG, Tang C, Kim YK, Ma B, Baluk P, Lin MI, McDonald DM, et al. (2006) Essential role of nitric oxide in VEGF-induced, asthma-like angiogenic, inflammatory, mucus, and physiologic responses in the lung. Proc Natl Acad Sci USA 103:11021-11026.

Bhaskaran M and Mohan M (2014) MicroRNAs: history, biogenesis, and their evolving role in animal development and disease. Vet Pathol 51:759-774. 
Bhaskaran M, Xi D, Wang Y, Huang C, Narasaraju T, Shu W, Zhao C, Xiao X, More $\mathrm{S}$, Breshears M, et al. (2012) Identification of microRNAs changed in the neonatal lungs in response to hyperoxia exposure. Physiol Genomics 44:970-980.

Blencowe H, Cousens S, Oestergaard MZ, Chou D, Moller AB, Narwal R, Adler A, Vera Garcia C, Rohde S, Say L, et al. (2012) National, regional, and worldwide estimates of preterm birth rates in the year 2010 with time trends since 1990 for selected countries: a systematic analysis and implications. Lancet 379:2162-2172.

Blonder JP, Mutka SC, Sun X, Qiu J, Green LH, Mehra NK, Boyanapalli R, Suniga M, Look K, Delany C, et al. (2014) Pharmacologic inhibition of S-nitrosoglutathione reductase protects against experimental asthma in BALB/c mice through attenuation of both bronchoconstriction and inflammation. BMC Pulm Med 14:3.

Bolton CE, Bush A, Hurst JR, Kotecha S, and McGarvey L (2015) Lung consequences in adults born prematurely. Thorax 70:574-580.

Britt Jr RD, Thompson MA, Kuipers I, Stewart A, Vogel ER, Thu J, Martin RJ, Pabelick CM, and Prakash YS (2015) Soluble guanylate cyclase modulators blunt hyperoxia effects on calcium responses of developing human airway smooth muscle. Am J Physiol Lung Cell Mol Physiol 309:L537-L542.

Brown-Steinke K, deRonde K, Yemen S, and Palmer LA (2010) Gender differences in S-nitrosoglutathione reductase activity in the lung. PLoS One 5:e14007.

Carlo WA, Finer NN, Walsh MC, Rich W, Gantz MG, Laptook AR, Yoder BA, Faix RG, Das A, Poole WK, et al.; SUPPORT Study Group of the Eunice Kennedy Shriver NICHD Neonatal Research Network (2010) Target ranges of oxygen saturation in extremely preterm infants. N Engl J Med 362:1959-1969.

De Boeck K, Smith J, Van Lierde S, and Devlieger H (1998) Response to bronchodilators in clinically stable 1-year-old patients with bronchopulmonary dysplasia. Eur J Pediatr 157:75-79.

Denjean A, Guimaraes H, Migdal M, Miramand JL, Dehan M, and Gaultier C (1992) Dose-related bronchodilator response to aerosolized salbutamol (albuterol) in ventilator-dependent premature infants. $J$ Pediatr 120:974-979.

Denjean A, Paris-Llado J, Zupan V, Debillon T, Kieffer F, Magny JF, Desfrères L, Llanas B, Guimaraes H, Moriette G, et al. (1998) Inhaled salbutamol and beclomethasone for preventing broncho-pulmonary dysplasia: a randomised doubleblind study. Eur $J$ Pediatr 157:926-931.

Dweep H, Gretz N, and Sticht C (2014) miRWalk database for miRNA-target interactions. Methods Mol Biol 1182:289-305.

Dweep H, Sticht C, Pandey P, and Gretz N (2011) miRWalk-database: prediction of possible miRNA binding sites by "walking" the genes of three genomes. $J$ Biomed Inform 44:839-847.

Evangelista AM, Rao VS, Filo AR, Marozkina NV, Doctor A, Jones DR, Gaston B, and Guilford WH (2010) Direct regulation of striated muscle myosins by nitric oxide and endogenous nitrosothiols. PLoS One 5:e11209.

Fang K, Johns R, Macdonald T, Kinter M, and Gaston B (2000) S-nitrosoglutathione breakdown prevents airway smooth muscle relaxation in the guinea pig. Am $J$ Physiol Lung Cell Mol Physiol 279:L716-L721.

Fawke J, Lum S, Kirkby J, Hennessy E, Marlow N, Rowell V, Thomas S, and Stocks J (2010) Lung function and respiratory symptoms at 11 years in children born extremely preterm: the EPICure study. Am J Respir Crit Care Med 182:237-245.

Ferrini ME, Simons BJ, Bassett DJ, Bradley MO, Roberts K, and Jaffar Z (2013) Snitrosoglutathione reductase inhibition regulates allergen-induced lung inflammation and airway hyperreactivity. PLoS One 8:e70351.

Filippone M, Carraro S, and Baraldi E (2013) The term "asthma" should be avoided in describing the chronic pulmonary disease of prematurity. Eur Respir $J \mathbf{4 2}$ $1430-1431$

Foster MW, Hess DT, and Stamler JS (2009) Protein S-nitrosylation in health and disease: a current perspective. Trends Mol Med 15:391-404.

Furman L, Baley J, Borawski-Clark E, Aucott S, and Hack M (1996) Hospitalization as a measure of morbidity among very low birth weight infants with chronic lung disease. $J$ Pediatr 128:447-452.

Gaston B, Drazen JM, Jansen A, Sugarbaker DA, Loscalzo J, Richards W, and Stamler JS (1994) Relaxation of human bronchial smooth muscle by S-nitrosothiols in vitro. J Pharmacol Exp Ther 268:978-984.

Gaston B, Sears S, Woods J, Hunt J, Ponaman M, McMahon T, and Stamler JS (1998) Bronchodilator S-nitrosothiol deficiency in asthmatic respiratory failure. Lancet 351:1317-1319.

Gomez-Del Rio M, Gerhardt T, Hehre D, Feller R, and Bancalari E (1986) Effect of a beta-agonist nebulization on lung function in neonates with increased pulmonary resistance. Pediatr Pulmonol 2:287-291.

Grasemann H, Gaston B, Fang K, Paul K, and Ratjen F (1999) Decreased levels of nitrosothiols in the lower airways of patients with cystic fibrosis and normal pulmonary function. J Pediatr 135:770-772.

Green LS, Chun LE, Patton AK, Sun X, Rosenthal GJ, and Richards JP (2012) Mechanism of inhibition for N6022, a first-in-class drug targeting S-nitrosoglutathione reductase. Biochemistry 51:2157-2168.

Greenough A (2006) Bronchopulmonary dysplasia: long term follow up. Paediatr Respir Rev 7(Suppl 1):S189-S191.

Greenough A (2013) Long-term respiratory consequences of premature birth at less than 32 weeks of gestation. Early Hum Dev 89(Suppl 2):S25-S27.

Grischkan J, Storfer-Isser A, Rosen CL, Larkin EK, Kirchner HL, South A, WilsonCostello DC, Martin RJ, and Redline S (2004) Variation in childhood asthma among former preterm infants. J Pediatr 144:321-326.

Gupta S, Prasanth K, Chen CM, and Yeh TF (2012) Postnatal corticosteroids for prevention and treatment of chronic lung disease in the preterm newborn. Int $J$ Pediatr 2012:315642.

Halvorsen T, Skadberg BT, Eide GE, Røksund O, Aksnes L, and Øymar K (2005) Characteristics of asthma and airway hyper-responsiveness after premature birth. Pediatr Allergy Immunol 16:487-494.

Hart TW (1985) Some observations concerning the S-nitroso and S-phenylsulfonyl derivatives of L-cysteine and glutathione. Tetrahedron Lett 26:2013-2016.

Iyengar A and Davis JM (2015) Drug therapy for the prevention and treatment of bronchopulmonary dysplasia. Front Pharmacol 6:12.
Jaakkola JJ, Ahmed P, Ieromnimon A, Goepfert P, Laiou E, Quansah R and Jaakkola MS (2006) Preterm delivery and asthma: a systematic review and meta-analysis. J Allergy Clin Immunol 118:823-830.

Janssen LJ, Premji M, Lu-Chao H, Cox G, and Keshavjee S (2000) NO(+) but not NO radical relaxes airway smooth muscle via cGMP-independent release of internal $\mathrm{Ca}(2+)$. Am J Physiol Lung Cell Mol Physiol 278:L899-L905.

Jobe AH (2011) The new bronchopulmonary dysplasia. Curr Opin Pediatr 23: $167-172$.

Kim DK, Choi SH, Yu J, Yoo Y, Kim Bl, and Koh YY (2006) Bronchial responsiveness to methacholine and adenosine $5^{\prime}$-monophosphate in preschool children with bronchopulmonary dysplasia. Pediatr Pulmonol 41:538-543.

Kovacs SJ, Fisher JB, Brodsky NL, and Hurt H (1990) Use of a beta-agonist in ventilated, very-low-birth-weight babies: a longitudinal evaluation. Dev Pharmacol Ther 15:61-67.

Laughon MM, Langer JC, Bose CL, Smith PB, Ambalavanan N, Kennedy KA, Stoll BJ, Buchter S, Laptook AR, Ehrenkranz RA, et al.; Eunice Kennedy Shriver National Institute of Child Health and Human Development Neonatal Research Network (2011) Prediction of bronchopulmonary dysplasia by postnatal age in extremely premature infants. Am J Respir Crit Care Med 183:1715-1722.

Lemons JA, Bauer CR, Oh W, Korones SB, Papile LA, Stoll BJ, Verter J, Temprosa M, Wright LL, Ehrenkranz RA, et al.; NICHD Neonatal Research Network (2001) Very low birth weight outcomes of the National Institute of Child health and human development neonatal research network, January 1995 through December 1996. Pediatrics 107:E1.

Lima B, Lam GK, Xie L, Diesen DL, Villamizar N, Nienaber J, Messina E, Bowles D, Kontos CD, Hare JM, et al. (2009) Endogenous S-nitrosothiols protect against myocardial injury. Proc Natl Acad Sci USA 106:6297-6302.

Liu L, Hausladen A, Zeng M, Que L, Heitman J, and Stamler JS (2001) A metabolic enzyme for S-nitrosothiol conserved from bacteria to humans. Nature 410: 490-494.

Lum S, Kirkby J, Welsh L, Marlow N, Hennessy E, and Stocks J (2011) Nature and severity of lung function abnormalities in extremely pre-term children at 11 years of age. Eur Respir J 37:1199-1207.

Maitre NL, Ballard RA, Ellenberg JH, Davis SD, Greenberg JM, Hamvas A and Pryhuber GS; Prematurity and Respiratory Outcomes Program (2015) Respiratory consequences of prematurity: evolution of a diagnosis and development of a comprehensive approach. J Perinatol 35:313-321.

Marozkina NV, Wang XQ, Stsiapura V, Fitzpatrick A, Carraro S, Hawkins GA, Bleecker E, Meyers D, Jarjour N, Fain SB, et al. (2015) Phenotype of asthmatics with increased airway S-nitrosoglutathione reductase activity. Eur Respir J 45: 87-97.

Marozkina NV, Wei C, Yemen S, Wallrabe H, Nagji AS, Liu L, Morozkina T, Jones $\mathrm{DR}$, and Gaston B (2012) S-nitrosoglutathione reductase in human lung cancer. Am J Respir Cell Mol Biol 46:63-70.

Mayer B, Pfeiffer S, Schrammel A, Koesling D, Schmidt K, and Brunner F (1998) A new pathway of nitric oxide/cyclic GMP signaling involving S-nitrosoglutathione. $J$ Biol Chem 273:3264-3270.

Mhanna MJ, Haxhiu MA, Jaber MA, Walenga RW, Chang CH, and Liu S, and Martin RJ (2004). Hyperoxia impairs airway relaxation in immature rats via a cAMPmediated mechanism. J Appl Physiol 96:1854-1860.

Mhanna MJ, Patel JS, Patel S, and Cohn R (2009) The effects of racemic albuterol versus levalbuterol in very low birth weight infants. Pediatr Pulmonol 44:778-783.

Motoyama EK, Fort MD, Klesh KW, Mutich RL, and Guthrie RD (1987) Early onset of airway reactivity in premature infants with bronchopulmonary dysplasia. Am Rev Respir Dis 136:50-57.

Moya MP, Gow AJ, Califf RM, Goldberg RN, and Stamler JS (2002) Inhaled ethyl nitrite gas for persistent pulmonary hypertension of the newborn. Lancet $\mathbf{3 6 0}$ 141-143.

Moya MP, Gow AJ, McMahon TJ, Toone EJ, Cheifetz IM, Goldberg RN, and Stamler JS (2001) S-nitrosothiol repletion by an inhaled gas regulates pulmonary function. Proc Natl Acad Sci USA 98:5792-5797.

$\mathrm{Ng}$ G, da Silva O, and Ohlsson A (2012) Bronchodilators for the prevention and treatment of chronic lung disease in preterm infants. Cochrane Database Syst Rev 6:CD003214.

Nold MF, Mangan NE, Rudloff I, Cho SX, Shariatian N, Samarasinghe TD, Skuza EM, Pedersen J, Veldman A, Berger PJ, et al. (2013) Interleukin-1 receptor antagonist prevents murine bronchopulmonary dysplasia induced by perinatal inflammation and hyperoxia. Proc Natl Acad Sci USA 110:14384-14389.

Northway WH, Jr, Rosan RC, and Porter DY (1967) Pulmonary disease following respirator therapy of hyaline-membrane disease: bronchopulmonary dysplasia. $N$ Engl J Med 276:357-368.

O'Reilly M, Harding R, and Sozo F (2014) Altered small airways in aged mice following neonatal exposure to hyperoxic gas. Neonatology 105:39-45.

Pabelick CM, Warner DO, Perkins WJ, and Jones KA (2000) S-nitrosoglutathioneinduced decrease in calcium sensitivity of airway smooth muscle. Am J Physiol Lung Cell Mol Physiol 278:L521-L527.

Pantalitschka T and Poets CF (2006) Inhaled drugs for the prevention and treatment of bronchopulmonary dysplasia. Pediatr Pulmonol 41:703-708.

Pelkonen AS, Hakulinen AL, Hallman M, and Turpeinen M (2001) Effect of inhaled budesonide therapy on lung function in schoolchildren born preterm. Respir Med 95:565-570.

Perkins WJ, Pabelick C, Warner DO, and Jones KA (1998) cGMP-independent mechanism of airway smooth muscle relaxation induced by S-nitrosoglutathione. Am J Physiol 275:C468-C474.

Potter CF, Kuo NT, Farver CF, McMahon JT, Chang CH, Agani FH, Haxhiu MA and Martin RJ (1999) Effects of hyperoxia on nitric oxide synthase expression, nitric oxide activity, and lung injury in rat pups. Pediatr Res 45:8-13.

Que LG, Liu L, Yan Y, Whitehead GS, Gavett SH, Schwartz DA, and Stamler JS (2005) Protection from experimental asthma by an endogenous bronchodilator. Science 308:1618-1621. 
Que LG, Yang Z, Stamler JS, Lugogo NL, and Kraft M (2009) S-nitrosoglutathione reductase: an important regulator in human asthma. Am J Respir Crit Care Med 180:226-231.

Raffay T, Kc P, Reynolds J, Di Fiore J, MacFarlane P, and Martin RJ (2014) Repeated $\beta 2$-adrenergic receptor agonist therapy attenuates the response to rescue bronchodilation in a hyperoxic newborn mouse model. Neonatology 106:126-132.

Regal JF, Lawrence BP, Johnson AC, Lojovich SJ, and O'Reilly MA (2014) Neonatal oxygen exposure alters airway hyper-responsiveness but not the response to allergen challenge in adult mice. Pediatr Allergy Immunol 25:180-186.

Rogers SC, Gibbons LB, Griffin S, and Doctor A (2013) Analysis of S-nitrosothiols via copper cysteine (2C) and copper cysteine-carbon monoxide (3C) methods. Methods 62:123-129.

Shalaby KH, Gold LG, Schuessler TF, Martin JG, and Robichaud A (2010) Combined forced oscillation and forced expiration measurements in mice for the assessment of airway hyperresponsiveness. Respir Res 11:82.

Siltanen M, Wehkalampi K, Hovi P, Eriksson JG, Strang-Karlsson S, Järvenpää AL, Andersson S, and Kajantie E (2011) Preterm birth reduces the incidence of atopy in adulthood. J Allergy Clin Immunol 127:935-942.

Slaughter JL, Stenger MR, Reagan PB, and Jadcherla SR (2014) Utilization of inhaled corticosteroids for infants with bronchopulmonary dysplasia. PLoS One $\mathbf{9}$ e106838.

Slaughter JL, Stenger MR, Reagan PB, and Jadcherla SR (2015) Inhaled bronchodilator use for infants with bronchopulmonary dysplasia. J Perinatol 35:61-66.

Smith PG, Dreshaj A, Chaudhuri S, Onder BM, Mhanna MJ, and Martin RJ (2007) Hyperoxic conditions inhibit airway smooth muscle myosin phosphatase in rat pups. Am J Physiol Lung Cell Mol Physiol 292:L68-L73.

Snyder AH, McPherson ME, Hunt JF, Johnson M, Stamler JS, and Gaston B (2002) Acute effects of aerosolized S-nitrosoglutathione in cystic fibrosis. Am J Respir Crit Care Med 165:922-926.

Sopi RB, Haxhiu MA, Martin RJ, Dreshaj IA, Kamath S, and Zaidi SI (2007) Disruption of NO-cGMP signaling by neonatal hyperoxia impairs relaxation of lung parenchyma. Am J Physiol Lung Cell Mol Physiol 293:L1029-L1036.

Stevens TP, Dylag A, Panthagani I, Pryhuber G, and Halterman J (2010) Effect of cumulative oxygen exposure on respiratory symptoms during infancy among VLBW infants without bronchopulmonary dysplasia. Pediatr Pulmonol 45:371-379.

Subbarao P and Ratjen F (2006) Beta2-agonists for asthma: the pediatric perspective. Clin Rev Allergy Immunol 31:209-218.

Tait BD and Miller JP (2014) Disease-modifying agents for the treatment of cystic fibrosis. Annu Rep Med Chem 49:317-330.

Takeda K, Okamoto M, de Langhe S, Dill E, Armstrong M, Reisdorf N, Irwin D, Koster M, Wilder J, Stenmark KR, et al. (2009) Peroxisome proliferator-activated receptor-g agonist treatment increases septation and angiogenesis and decreases airway hyperresponsiveness in a model of experimental neonatal chronic lung disease. Anat Rec 292:1045-1061.

Tan X, Alrashdan YA, Alkhouri H, Oliver BG, Armour CL, and Hughes JM (2013) Airway smooth muscle CXCR3 ligand production: regulation by JAK-STAT1 and intracellular $\mathrm{Ca}^{2+}$. Am J Physiol Lung Cell Mol Physiol 304:L790-L802.

Thébaud B and Abman SH (2007) Bronchopulmonary dysplasia: where have all the vessels gone? Roles of angiogenic growth factors in chronic lung disease. Am J Respir Crit Care Med 175:978-985.

Van Marter LJ (2009) Epidemiology of bronchopulmonary dysplasia. Semin Fetal Neonatal Med 14:358-366.

Vollsæter M, Røksund OD, Eide GE, Markestad T, and Halvorsen T (2013) Lung function after preterm birth: development from mid-childhood to adulthood. Tho$\operatorname{rax}$ 68:767-776.

Vrijlandt EJ, Gerritsen J, Boezen HM, Grevink RG, and Duiverman EJ (2006) Lung function and exercise capacity in young adults born prematurely. Am J Respir Crit Care Med 173:890-896

Wang H, Jafri A, Martin RJ, Nnanabu J, Farver C, Prakash YS, and MacFarlane PM (2014) Severity of neonatal hyperoxia determines structural and functional changes in developing mouse airway. Am J Physiol Lung Cell Mol Physiol 307: L295-L301.

Warner BB, Stuart LA, Papes RA, and Wispé JR (1998) Functional and pathological effects of prolonged hyperoxia in neonatal mice. Am J Physiol 275:L110-L117.

Whalen EJ, Foster MW, Matsumoto A, Ozawa K, Violin JD, Que LG, Nelson CD, Benhar M, Keys JR, Rockman HA, et al. (2007) Regulation of beta-adrenergic receptor signaling by S-nitrosylation of G-protein-coupled receptor kinase 2. Cell 129:511-522.

White TA, Walseth TF, and Kannan MS (2002) Nitric oxide inhibits ADP-ribosyl cyclase through a cGMP-independent pathway in airway smooth muscle. Am $J$ Physiol Lung Cell Mol Physiol 283:L1065-L1071.

Wilkie RA and Bryan MH (1987) Effect of bronchodilators on airway resistance in ventilator-dependent neonates with chronic lung disease. J Pediatr 111:278-282.

Yuksel B and Greenough A (1993) Variable response to bronchodilator therapy in young children born prematurely. Respir Med 87:359-364.

Address correspondence to: Dr. Benjamin Gaston, Rainbow Babies and Children's Hospital/Case Western Reserve University, Department of Pediatrics, Division of Pulmonology, 2109 Adelbert Road, BRB 827, Cleveland, OH 44106-6010. E-mail: benjamin.gaston@case.edu 